\title{
Chapter 22 \\ Optimal Design \\ of Environmental-Friendly Hybrid \\ Power Generation System
}

\author{
Seyed Vahid Hosseini, Ali Izadi, Afsaneh Sadat Boloorchi, \\ Seyed Hossein Madani, Yong Chen, and Mahmoud Chizari
}

\begin{abstract}
Combination of both renewable and fuel-based generation systems is an advantageous approach to develop off-grid distributed power plants. This approach requires evaluation of the techno-economic potential of each source in a selected site as well as optimization of load sharing strategy between them. Development of a remote hybrid power plant in an off-grid area is the interest of this study. Defining all available combinations, characteristics of performance, cost and availability of them evaluated. Applying constraints, multi-objective target domain based on load following and Levelized Cost of Electricity is established in which by utilizing Pareto front approach, optimized scenarios is achieved.
\end{abstract}

Keywords Hybrid power generation $\cdot$ Solar $\cdot$ Wind $\cdot$ Energy $\cdot$ Micro gas turbine $\cdot$ Micro grid $\cdot$ Micro power plant

\subsection{Introduction}

For many under-development countries, hybrid generation systems are the solution which could satisfy various requirements of power generation including availability, renewability and cost. The authors presented a procedure to evaluate the performance and economy of a hybrid system of wind, photovoltaic (PV) and Micro Gas Turbine (MGT) with the required battery capacity in a remote area in South Africa as a test case in [1] and suggest optimization to size of a hybrid system of all resources.

The optimization of the power plant can be considered in two groups of conventional and new generation methods [2]. The conventional methods include the tradeoff approaches, iterative approaches, linear and mixed integer linear programming.

S. Hosseini $(\bowtie) \cdot$ Y. Chen $\cdot$ M. Chizari

Univesity of Hertfordshire, Hatfield, UK

e-mail: v.hosseini@herts.ac.uk

A. Izadi $\cdot$ S. H. Madani

Samad-Power Ltd, Milton Keynes, UK

A. S. Boloorchi

Turbotec Co, Tehran, Iran

(C) The Author(s) 2021

I. Mporas et al. (eds.), Energy and Sustainable Futures, Springer Proceedings in Energy,

https://doi.org/10.1007/978-3-030-63916-7_22 
The new generation approaches, on the other hand, integrate mathematical models with the computer programs in the heuristic manner to obtain a solution [3].

To find the optimum size of a hybrid system with solar PV and wind generators, a harmony search method is employed in [4]. In this order, several configurations are defined as "Harmony". Sizes of solar PV generators and wind turbines, as well as estimated costs of the system, are specified in each harmony. Considering optimization targets, discrete search technique employed to find the solution.

In current study, Levelized Cost of Electricity (LCOE) [5] and load following of the generation system is considered as the target objects. The procedure is adopted in a rural area near Cape Town, South Africa and to apply direct optimization, solution domain of all scenarios using defined available sources is constructed. Various aspects of scenarios are investigated. Then, Pareto front technique is employed to obtain the optimum solution.

\subsection{Theory and Methodologies}

To define the solution domain, combinations of Capstone MGT30, MGT65 and MGT $200 \mathrm{~S}$ with 0 to 4 wind turbine of $100 \mathrm{~kW}$ power are considered. The size of Solar PV in each configuration is obtained based on the assumption of providing at least $90 \%$ of the demand load in the worst month of each scenario. Therefore, 45 scenarios are extracted which are listed in Table 22.1.

Since there are a finite number of scenarios, the direct optimisation technique is employed to find the solution. In this method, techno-economic parameters of all scenarios are evaluated which make it possible to select the global optimal solution. Various parameters could be defined to show the performance, cost and availability of the system among which annual generation, Levelized Cost of Electricity (LCOE), load following deviation, nominal capacity, number of days with 1 hour shortage or blackout, and renewability of the hybrid generation system is considered to trim unpractical scenarios.

Table 22.1 Available scenarios

\begin{tabular}{|c|c|c|c|c|c|c|}
\hline & & \multicolumn{5}{|c|}{ Wind Turbine } \\
\hline & & $\mathbf{0}$ & 100 & 200 & 300 & 400 \\
\hline \multirow{9}{*}{$\stackrel{5}{\Sigma}$} & $\overline{0}$ & 2680 & 1520 & 610 & 180 & 0 \\
\hline & 30 & 2200 & 1070 & 300 & 40 & 0 \\
\hline & 65 & 1640 & 560 & 130 & 0 & 0 \\
\hline & $30+65$ & 1170 & 280 & 0 & 0 & 0 \\
\hline & $2 \times 65$ & 610 & 80 & 0 & 0 & 0 \\
\hline & $2 \times 65+30$ & 260 & 0 & 0 & 0 & 0 \\
\hline & $3 \times 65$ & 40 & 0 & 0 & 0 & 0 \\
\hline & 200 & 10 & 0 & 0 & 0 & 0 \\
\hline & $200+30$ & 0 & 0 & 0 & 0 & 0 \\
\hline
\end{tabular}




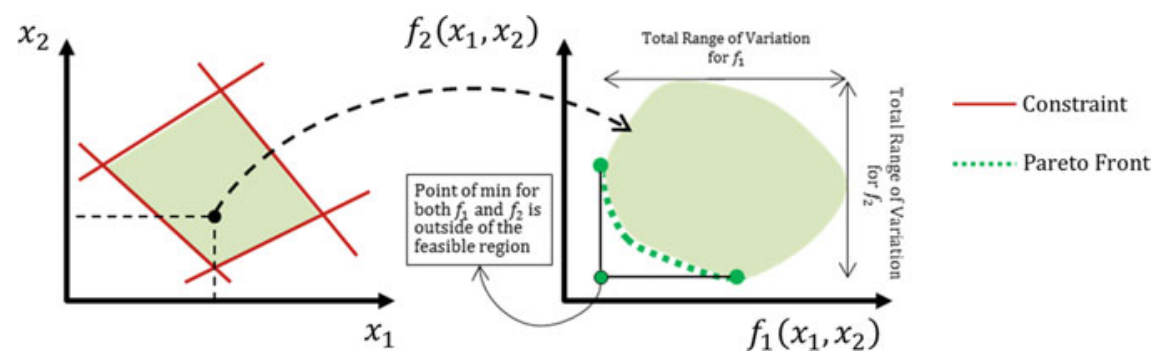

Fig. 22.1 The Pareto front in a multi-objective optimisation domain

LCOE are selected as the objectives for the optimization process that means the desired hybrid power plant not only have to track the demand load profile but also provide the electricity in minimum LCOE. To quantify the load following behaviour, least square of the difference between monthly load demand and generation is considered as the deviation parameter.

Based on the objectives' characteristics which are in contrary to each other the Pareto Front approach is applied to find the optimum. This method which is illustrated schematically in Fig. 22.1 generally employed when minimising one of the targets yields to increase of the other ones. Any of the scenarios which are places on the Pareto front could be selected as an optimum solution regarding the weight of each target for a project.

\subsection{Results and Discussion}

A rural area near Cape Town is considered as a case study in this article and extracted techno-economic parameters of all 45 scenarios are plotted in Fig. 22.2. It is obviously clear that some of the scenarios generate several times higher than the annual required load. Therefore, to achieve a better optimization domain, some of them are ignored by applying two following constraints:

- Size: Annual generation of the system should be less than 2,500,000 kWh.

- Availability: There should be no days with more than $1 \mathrm{~h}$ no generation situation.

- Renewability: Utilization of renewable sources should be more than $20 \%$ of overall generation.

Although the values for these constrain are specified, other values or constraints may be added due to the condition of a project. The remaining scenarios are indicated in Table 22.2. All of the scenarios with no MGT are eliminated because of the availability constrains and the others eliminated by size and renewability ones. In 


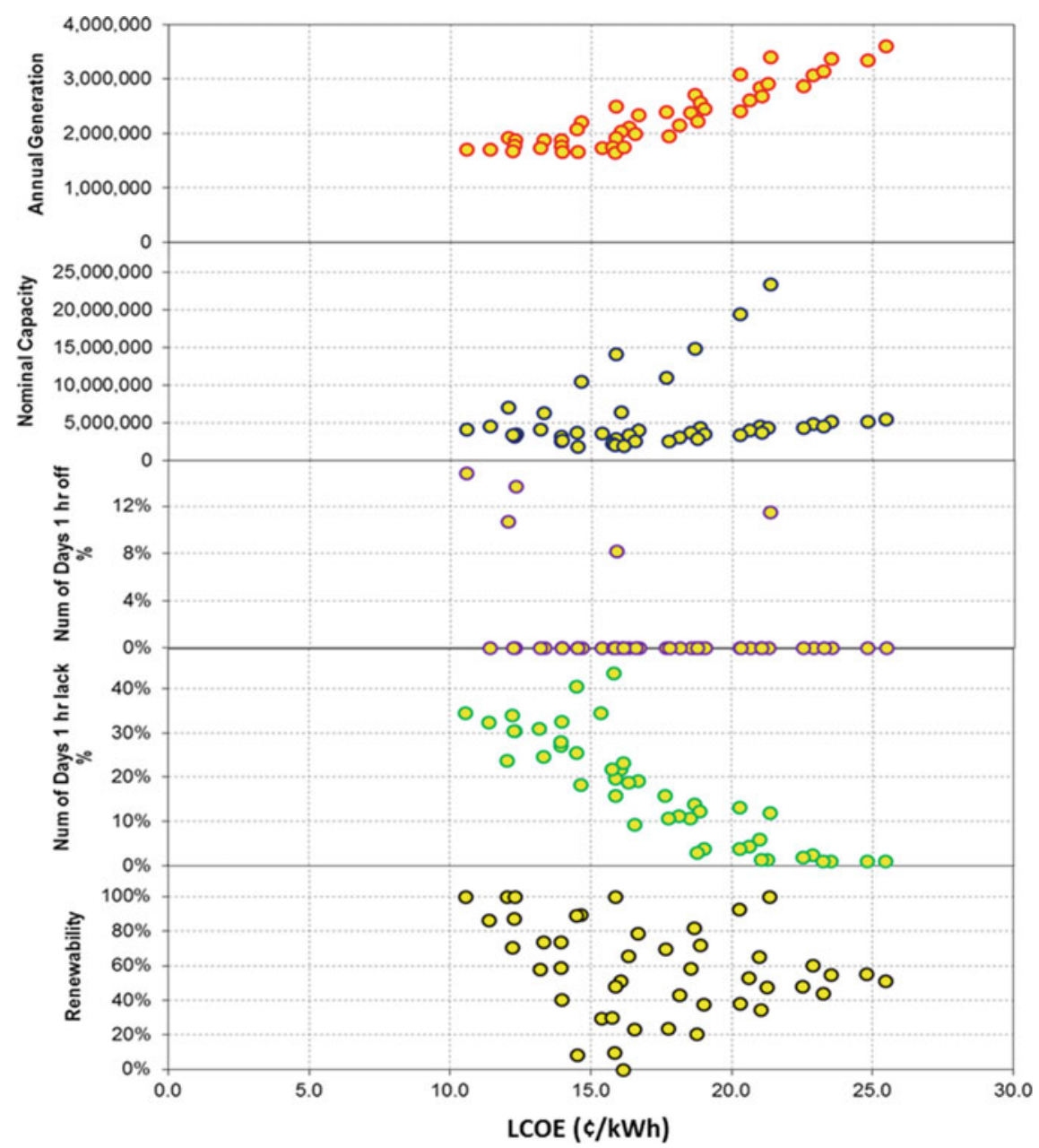

Fig. 22.2 Techno-economic parameters of all scenarios

remaining scenarios, some of them benefit from only two sources which means those do not include either any wind turbine or any solar PV. In Fig. 22.3 these two-source system are compared with the three-source systems in optimization targets domain which shows the effect of hybridization in improving both technical and economic aspects of the system.

Multi-objective optimization domain of the remaining 24 scenarios as well as the illustration of Pareto line is plotted in Fig. 22.4. Pareto front is passing through three following scenarios: 
Table 22.2 Remaining scenarios after applying size, availability and renewability constraints

\begin{tabular}{|c|l|c|c|c|c|c|}
\cline { 3 - 7 } \multicolumn{2}{c|}{} & \multicolumn{5}{c|}{ Wind Turbine } \\
\cline { 3 - 7 } \multicolumn{2}{c|}{} & $\mathbf{0}$ & $\mathbf{1 0 0}$ & $\mathbf{2 0 0}$ & $\mathbf{3 0 0}$ & $\mathbf{4 0 0}$ \\
\hline \multirow{3}{*}{} & $\mathbf{0}$ & 2680 & 1520 & 610 & 180 & 0 \\
\cline { 2 - 7 } & $\mathbf{3 0}$ & 2200 & 1070 & 300 & 40 & 0 \\
\cline { 2 - 7 } & $\mathbf{6 5}$ & 1640 & 560 & 130 & 0 & 0 \\
\cline { 2 - 7 } & $\mathbf{3 0}+\mathbf{6 5}$ & 1170 & 280 & 0 & 0 & 0 \\
\cline { 2 - 7 } & $\mathbf{2} \times \mathbf{6 5}$ & 610 & 80 & 0 & 0 & 0 \\
\cline { 2 - 8 } & $\mathbf{2} \times \mathbf{6 5}+\mathbf{3 0}$ & 260 & 0 & 0 & 0 & 0 \\
\cline { 2 - 8 } & $\mathbf{3} \times \mathbf{6 5}$ & 40 & 0 & 0 & 0 & 0 \\
\cline { 2 - 8 } & $\mathbf{2 0 0}$ & 10 & 0 & 0 & 0 & 0 \\
\cline { 2 - 8 } & $\mathbf{2 0 0 + 3 0}$ & 0 & 0 & 0 & 0 & \\
\hline
\end{tabular}

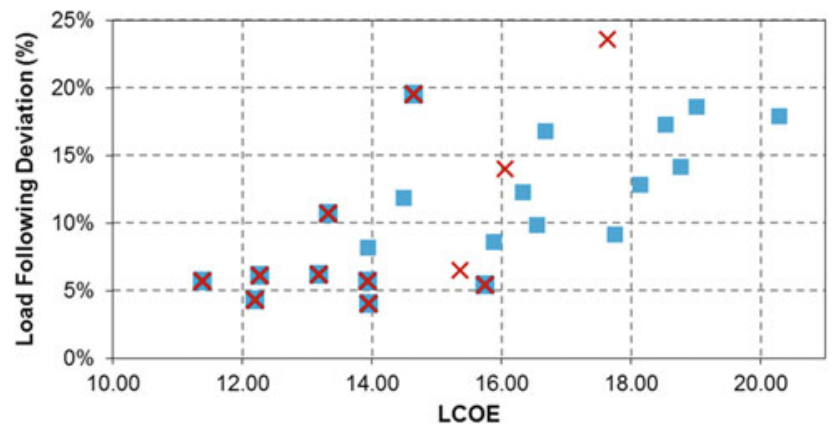

$\times M G T+P V($ No $W T)$ $=M G T+W T($ No Solar PV) *All Sources (MGT+WT+PV)

Fig. 22.3 Comparison between two-source and three-source systems

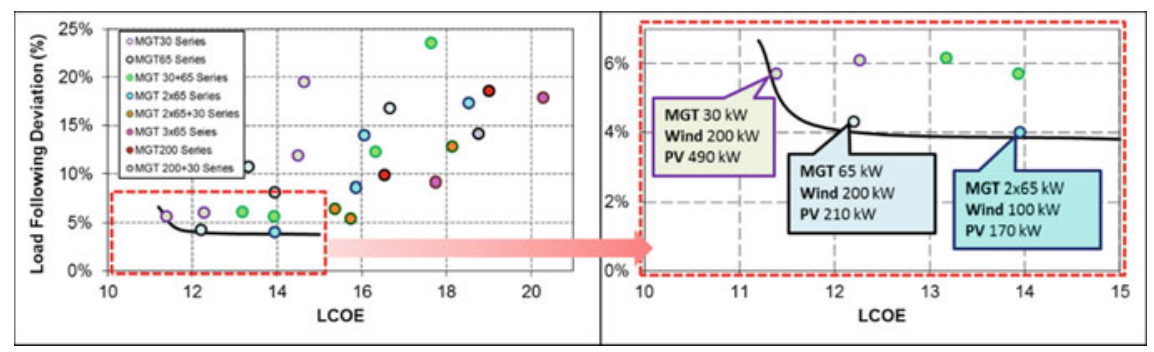

Fig. 22.4 Multi-objective domain and Pareto front

1- MGT $30 \mathrm{~kW}$, WT $2 \times 100 \mathrm{~kW}$, PV $490 \mathrm{~kW}$, Battery $1640 \mathrm{kWh}$

2- MGT $65 \mathrm{~kW}$, WT $2 \times 100 \mathrm{~kW}$, PV $220 \mathrm{~kW}$, Battery $1800 \mathrm{kWh}$

3- MGT $2 \times 65 \mathrm{~kW}$, WT $100 \mathrm{~kW}$, PV $170 \mathrm{~kW}$, Battery $1530 \mathrm{kWh}$

It could be seen that by increasing the size of the MGT, the load following behaviour of the system is improved but the LCOE is increased. Load following of these three optimum solutions is also plotted in Fig. 22.5 which shows more deviation in small MGT scenario. 


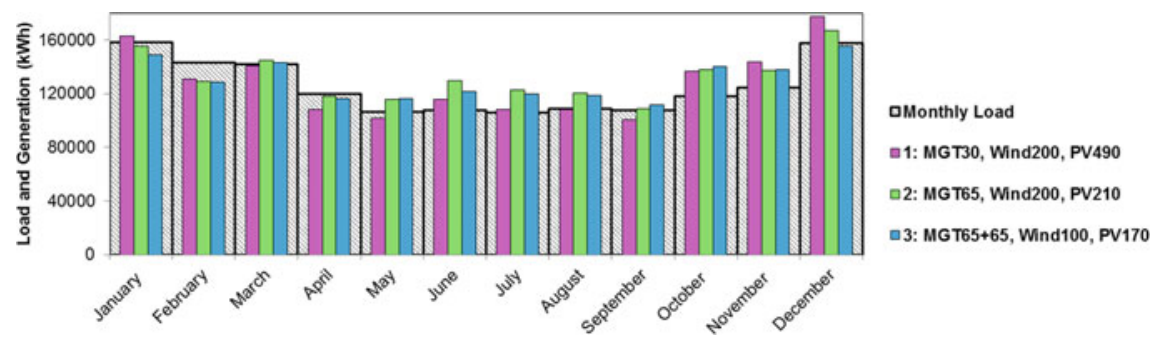

Fig. 22.5 Load following deviation of the selected scenarios

This Pareto front provides optimum solutions based on the selected targets as well as required data for decision makers. Having all optimum solution in hand, one may consider weights for each target and select the most appropriate one based on especial condition of the project.

\subsection{Conclusion}

Techno-economic parameters of all available solutions employing 30,65 and $200 \mathrm{~kW}$ MGTs, as well as 0 to 4 sets of wind turbine in combination with appropriate solar $\mathrm{PV}$, are evaluated. Applying size, availability and renewability constraints, some of the scenarios were eliminated. Among the remaining ones, load following behaviour and LCOE were considered as the target and the multi-objective Pareto front was obtained. It was shown that combining both three resources yields to enhancement of the overall techno-economic parameters of the system. The authors recommend that this procedure could be improved by employing a wider range of wind turbines. The criteria of suppling at least $90 \%$ of monthly loads to size the solar PV could also be investigated.

\section{References}

1. S.V. Hosseini, H. Madani, A. Izadi, M. Chizari, Design procedure of a hybrid renewable power generation system, in International Conference on Energy and Sustainable Futures (ICESF), Hatfield (2020)

2. W.L. Theo, J.S. Lim, W.S. Ho, H. Hashim, C.T. Lee, Review of distributed generation (DG) system planning and optimisation techniques: Comparison of numerical and mathematical modelling methods, Renewable and Sustainable Energy Reviews, vol. 67 (2017)

3. S. Twaha, M.A. Ramli, A review of optimization approaches for hybrid distributed energy generation systems: off-grid and grid-connected systems. Sustainable Cities and Soc. 41 (2018) 
4. A. Askarzadeh, Developing a discrete harmony search algorithm for size optimization of windphotovoltaic hybrid energy system. Solar Energy 98 (2013)

5. M. Bortolini, M. Gamberi, A. Graziani, F. Pilati, Economic and environmental bi-objective design of an off-grid photovoltaic-battery-diesel generator hybrid energy system. Energy Conver. Manag. 106 (2015)

Open Access This chapter is licensed under the terms of the Creative Commons Attribution 4.0 International License (http://creativecommons.org/licenses/by/4.0/), which permits use, sharing, adaptation, distribution and reproduction in any medium or format, as long as you give appropriate credit to the original author(s) and the source, provide a link to the Creative Commons license and indicate if changes were made.

The images or other third party material in this chapter are included in the chapter's Creative Commons license, unless indicated otherwise in a credit line to the material. If material is not included in the chapter's Creative Commons license and your intended use is not permitted by statutory regulation or exceeds the permitted use, you will need to obtain permission directly from the copyright holder. 